\title{
Physiological Workload during Rescue Drills at Sea Level and at Geographical Altitude in Chile
}

\author{
Esteban Oñate and Elías Apud* \\ Department of Ergonomics, University of Concepción, Barrio Universitario s/ , \\ Concepción, Chile \\ *Corresponding Author: Elías Apud, Department of Ergonomics, University of \\ Concepción, Barrio Universitario s/n, Concepción, Chile.
}

Received: February 13, 2021

Published: March 20, 2021

(C) All rights are reserved by Esteban Oñate and Elías Apud.

\begin{abstract}
Most large companies and institutions have emergency brigades to deal with potential risks. Furthermore, they must have good organizational systems to react quickly and efficiently to take control and protect affected populations. Therefore, it is very important in these jobs with high physiological demands to organize the activities to balance the workload between the members of the rescue teams. For this reason, on-site drills are useful to analyse the organization of work with concrete data which provide information to prevent brigade members from collapsing due to fatigue. Consequently, the objective of the present study was to determine the level of physiological load imposed by the activities carried out during three rescue drills of injured workers. Two of them were carried out at sea level and a third at 4300 meters above sea level (m.a.s.l.). The results revealed significant differences in the physiological load between the members of the brigades in the three evaluations. It was found that some of them reached dangerous levels overloading their cardiovascular system over $80 \%$ and even $100 \%$ of their estimated maximal heart rate. Among the results, the positive correlation between the average heart rate achieved in the drills and the Body Mass Index (BMI) stands out, revealing that the overweight members of the brigades worked with higher cardiovascular load levels than those with normal weight. The results allow to conclude that the distribution of activities should be re-examined to evaluate alternatives aimed at balancing the intensity of the efforts. It is also recommended that the emergency brigades participate in regular physical training programs and educate them in eating habits to reduce their trend to overweight.
\end{abstract}

Keywords: Emergency Brigades; Overweight; Physiological Workload; Rescue Drills; Training

\section{Abbreviations}

BMI: Body Mass Index; HR: Heart Rate; NFPA: National Fire Protection Association; UNISDR: United Nations Office for Disaster Risk Reduction; WHO: World Health Organization

\section{Introduction}

In Chile, numerous serious emergencies have occurred in the last decade, including earthquakes, tsunamis, volcanic eruptions, floods, landslides and large-scale rural fires. Because of these disasters, the country has had to mourn the loss of many human lives. In addition, according to the UNISDR [1], Chile is among the
10 countries in the world with the highest expenditure due to natural disasters in recent times. Unfortunately, many disasters such as earthquakes, are almost impossible to predict and therefore it is very important to have good organizational systems to react quickly. An important aspect is that, even with the most sophisticated technological resources, the role of the emergency brigades is fundamental to take control and protect the affected populations.

What has been highlighted in relation to natural disasters is also valid for the control of emergencies in industries. In some cases, accidents occur as a result of the aforementioned natural disasters, 
but it is also common for work-related accidents which occur in different types of industries and institutions. There are some companies that have well-prepared teams, such as the brigades that fight forest fires [2]. The impact of high physiological load, product of heat and physical work, has been well documented [3]. Nowadays, based on such studies, there are strict criteria for medical, psychological and physiological selection of applicants before entering the brigades. In some companies they are also subjected to physical training programs. Unfortunately, this is not always the case and the emergency brigades are made up of people who perform different types of work, including some with sedentary activities. They only receive instruction to respond in case of emergencies, without measuring the impact that the severity and duration of the contingency may have on the brigade members. In other words, a worker in an advanced state of fatigue, will not be able to contribute to the control of the emergency and may put his life and that of other people at risk.

Therefore, to reduce risks, it is important that the brigades are made up of suitable men and women. It is also necessary to organize work to achieve balance among the members of an emergency brigade. In this context, drills that approach a real situation are very useful for analysing different aspects of work organization.

\section{Objective of the Study}

The objective of this study was to determine, in a company that sought to optimize working conditions for its brigades, the distribution of the physiological load of workers who carried out the simulation of three rescues of injured people at sea level and at 4300 m.a.s.l.

\section{Materials and Methods}

The study was carried out in a company that had well-established brigades. For the purpose of this study three drills were evaluated. Two of them were carried out at the company's premises at sea level, where two rescues were performed as a result of the simulation of an earthquake. The third drill was the rescue of an injured worker in the cab of a high tonnage truck, carried out at 4300 m.a.s.l. A total of 13 male rescuers who worked mostly in sedentary activities in their daily routines were evaluated. The sampling was for convenience since the workers were chosen from voluntary members according the facilities given by the company. All of them had a medical pass to integrate the brigades and specially for working at high altitude. Their also wore safety equipment for the drills they had to face. In the case of the evaluation at sea level the workers in the front line used autonomous breathing equipment. Prior to the initiation of the study a meeting was sustained with the workers where the aim of the study was explained to obtain their consent to participate in the evaluations.

Age, body mass and height were recorded in each worker with a Detecto ${ }^{\circledR}$ brand clinical scale. The body mass index (BMI) was obtained by dividing the kilograms of body weight by the height expressed in meters squared $\left(\mathrm{kg} / \mathrm{m}^{2}\right)$. As an indicator of physiological load, the heart rate of the brigade members was recorded simultaneously, every five seconds in each drill, using Polar ${ }^{\circledR}$ equipment. In addition, times and activities performed during the simulation were recorded.

Drills at sea level, rescue workers injured by earthquake and tsunami

All company workers who performed activities at sea level participated in this drill. Those who were not directly involved went to a safe place while the rescue manoeuvres were carried out. Seven brigade members were separated into two groups to rescue two injured persons, one of them unconscious and the other with a fracture in his lower limb.

Rescue of an unconscious worker in an environment with hydrogen sulphide

A group of three brigade members rescued an unconscious worker. Two of them, who entered the critical area, used autonomous breathing equipment, special helmet, protective clothing, special gloves and had the support of an ambulance and an emergency car. Figure 1 shows a brigade member equipped for work. This drill started at 11:42 a.m. and lasted 40 minutes. The workers showed up at the place where the victim was at 12:00 hrs.

\section{Rescue drill of a worker with a broken leg}

Four brigade members participated in the rescue of an operator with a fracture in one of his lower limbs. Figure 2 shows part of the activities carried out by rescuers. 


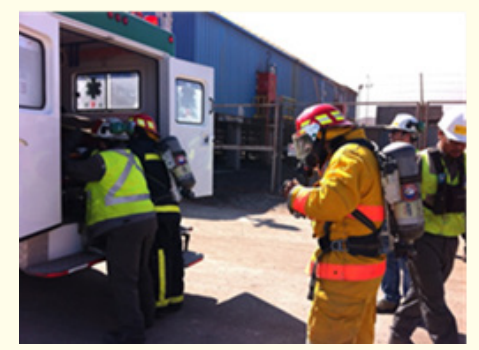

Figure 1: Worker with protective clothing and equipment.

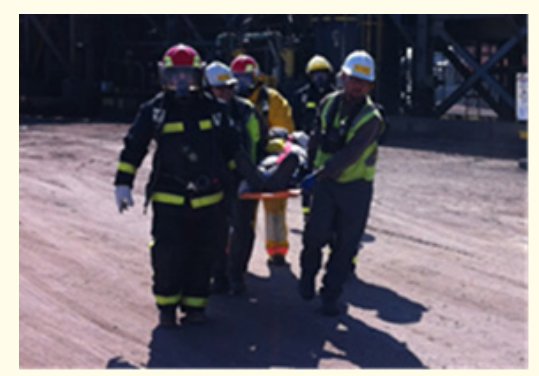

Figure 2: Transfer of the injured worker on a stretcher.

Unconscious truck operator rescue drill, from inside the cab, performed at an average height of $\mathbf{4 2 0 0}$ meters above sea level

Six brigade members participated during the drill. They made a quick assessment of the conditions and then proceeded to carry out the rescue using ropes to lower the worker from the cabin onto a stretcher. Figure 3 shows some of the work carried out by this crew.

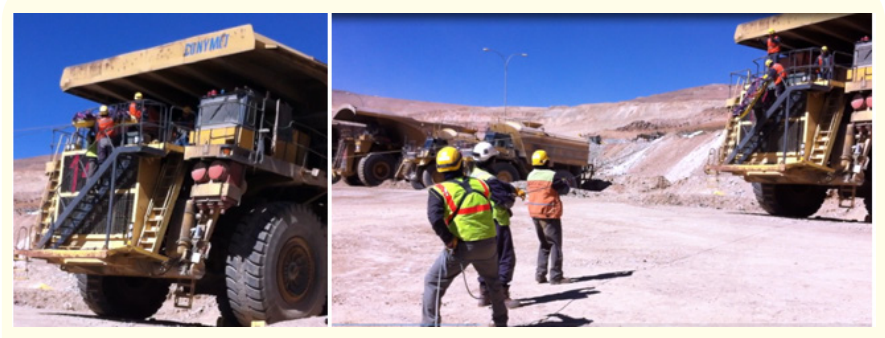

Figure 3: Rescue drill of an unconscious operator from the cab of a truck.

\section{Results and Discussion}

Table 1 shows the characteristics of the evaluated workers.

\begin{tabular}{|c|c|c|c|c|}
\hline \multicolumn{5}{|c|}{ Evaluated rescue workers (n = 13) } \\
\hline Variable & Mean & Minimum & Maximum & St. Dev. \\
\hline Age, years & 36.8 & 30.0 & 44.0 & 4.72 \\
\hline Body weight, kg & 72.7 & 53.0 & 83.0 & 8.65 \\
\hline Stature, cm & 167.1 & 150.0 & 172.0 & 5.74 \\
\hline BMI, kg/m ${ }^{2}$ & 26.0 & 22.8 & 28.7 & 2.17 \\
\hline Heart rate, beats/minute & 116.9 & 91.0 & 145.5 & 15.37 \\
\hline $\begin{array}{c}\text { Heart rate peak, beats/ } \\
\text { minute }\end{array}$ & 160.7 & 141.0 & 191.0 & 14.05 \\
\hline
\end{tabular}

Table 1: Mean value, minimum, maximum and standard deviation (St. Dev.) of a sample of 13 rescue workers. The same table includes the average and peak heart rate reached by the brigade members during the drills in which they participated.

The average BMI, which reaches a value of 26 , reveals overweight according to the World Health Organization, which indicates that when the BMI is equal to or greater than 25 people are overweight and obese when the BMI is equal to or greater than 30 [4]. In the case of the sample studied, there were no obese subjects, but $61.5 \%$ were overweight, which is important in emergency brigades that are exposed to levels of effort that can be very high and often of unpredictable duration. The statistical analysis summarized in table 2, which shows the comparison between workers with a BMI below and above 25, reveals, as expected, that there are statistically significant differences in BMI and weight in both groups. In the case of body mass, the normal group had an average weight $13.5 \mathrm{~kg}$ lower than the overweight group. In table 2, it can also be seen that the average heart rate during drills was significantly higher in the overweight workers.

The association between overweight and average heart rate is confirmed in the correlation analysis summarized in figure 4 , which illustrates that the higher the body weight the higher the heart rate in the evaluated simulations. The correlation coefficient, $r=0.837$, is highly significant, corroborating the relationship between both variables. This could be explained by the higher energy expenditure that people reach when they move their body mass [5]. 


\begin{tabular}{|c|c|c|c|c|c|}
\hline Variable & Normal body weight $(n=5)$ & Overweight $(n=8)$ & t-value & df & $\mathbf{p}$ \\
\hline Age, years & 36.4 & 37.1 & -0.26 & 11 & 0.801 \\
\hline Body weight, kg & 64.4 & 77.9 & -4.25 & 11 & 0.001 \\
\hline Stature, $\mathrm{cm}$ & 164.8 & 168.5 & -1.15 & 11 & 0.276 \\
\hline $\mathrm{BMI}, \mathrm{kg} / \mathrm{m}^{2}$ & 23.6 & 27.5 & -7.20 & 11 & 0.000 \\
\hline HR in emergency drills, beats/minute & 106.5 & 124.3 & -2.34 & 11 & 0.041 \\
\hline HR peak in emergency drills, beats/minute & 153.8 & 165.0 & -1.46 & 11 & 0.171 \\
\hline
\end{tabular}

Table 2. Comparison of some variables measured in workers of normal weight and workers with overweight.

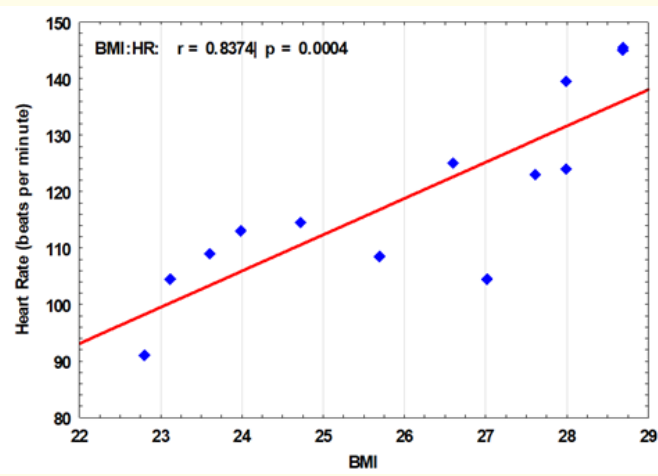

Figure 4: Correlation between BMI and average heart rate obtained during accident drills.

It could be argued that figure 1 does not distinguish between drills carried out at sea level and at geographical height, which is true, but looking at figure 5 , in which only the workers who did the rescue at geographical height are, the trend is the same; The two workers with a BMI under 25 have significantly lower average HR than those of their colleagues who exceeded this level (t-test, p < 0.005).

Regarding the intensity of the efforts, it is not the same to carry out rescue work at sea level than at 4300 m.a.s.l. The recommended limits for average heart rate for work at height and at sea level can be estimated according to what is summarized in table 3 .

Regarding the recommended heart rate values, is necessary emphasize that they must be considered only as a reference, since more research is required particularly in geographical altitude

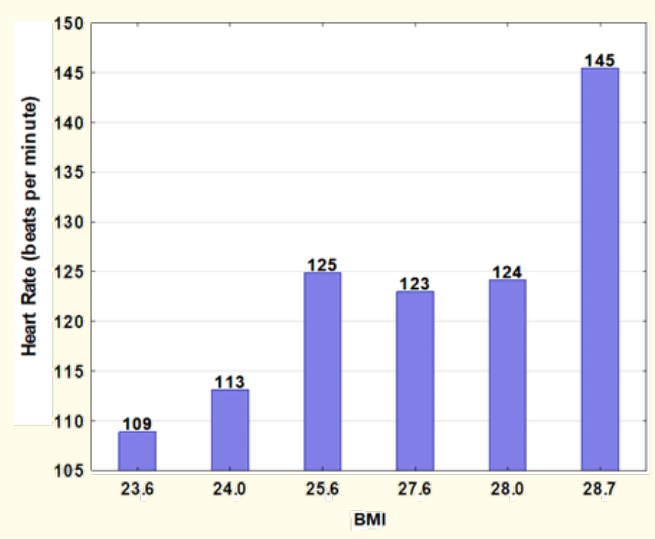

Figure 5: BMI and average heart rate of six workers evaluated at high altitude.

[6]. One of the main problems in discerning the limits of effort at geographical height, even in acclimatized individuals, is that the capacity to carry out dynamic efforts, namely the aerobic capacity decreases [7]. A reduction in maximum heart rate has also been described, but studies show much dispersion and have been carried out with small samples to set reference criteria applicable to workers of different ages [8]. In addition, it is necessary to consider working hours of different duration and even exposure to different heights in the same job. In the meantime, while more precise limits of dynamic physiological load are elucidated, work activities should not expose workers to excessive loads, particularly those with cardiovascular risk factors. Although the lack of precise references is a limitation, there is no doubt that the greatest risks occur when activities, even if isolated, impose high demands and workers reach peak heart rates [6]. This is precisely what happens with res- 


\begin{tabular}{|c|c|c|}
\hline Age range & HR sea level & HR high altitude \\
\hline $20-24$ & 115 & 99 \\
\hline $25-29$ & 112 & 96 \\
\hline $30-34$ & 110 & 94 \\
\hline $35-39$ & 108 & 92 \\
\hline $40-44$ & 106 & 90 \\
\hline $45-49$ & 104 & 88 \\
\hline $50-54$ & 102 & 86 \\
\hline $55-59$ & 100 & 84 \\
\hline
\end{tabular}

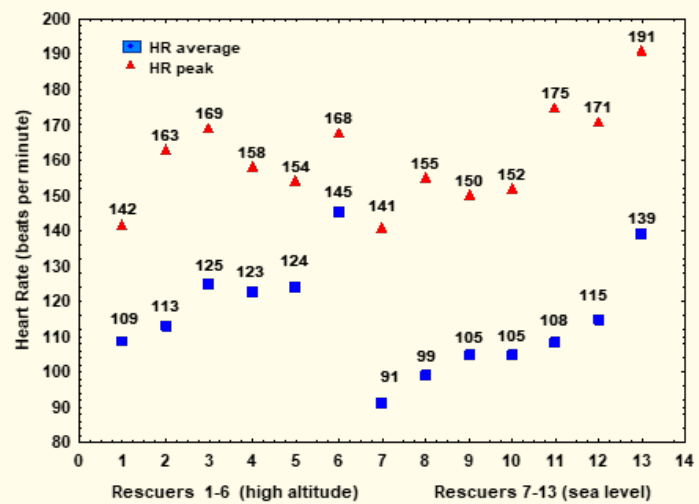

Table 3: Suggested limits of average HR for a working day at sea level and at altitudes ranging between 3800 and 4200 meters for people of different ages [6].

cuers when they have to deal with emergencies in which the speed of response is essential to address the risks, which can be very different in terms of complexity and time required to control them. To illustrate this, figure 6 shows the average and peak heart rate reached by each of the evaluated brigade members. The workers numbered from 1 to 6 correspond to those who carried out the rescue at geographical height, while those numbered from 7 to 13 are the brigade members who carried out the two rescues at sea level. The graph allows to see the variations in the physiological response case by case and, in both conditions, it is striking that the mean heart rates had a significant range of variation. In altitude workers, rescuer number 6 undoubtedly has a significantly higher mean heart rate than the rest of his colleagues. In the case of sea level rescues, worker number 13 has significantly higher heart rates than his peers. Continuing with the average heart rate, all the brigade members who participated in the rescues at geographic height reached mean values higher than those recommended in table 2 for prolonged work. In contrast, at sea level, only two of the total of seven workers involved exceed the recommended average limits for their age. Although the working periods are relatively short, the most worrying are the peak loads both at height and at sea level.

Looking at figure 6, it can be seen that in rescues at sea level, a brigade member reaches a peak of 191 beats per minute and six out of seven workers peak over 150 beats per minute. It is interesting to observe that at sea level the differences between aver-

age and peak heart rates are greater than at geographical height. However, as mentioned before, the maximum heart rate tends to decrease with height, so that the peak loads under such conditions are equally excessive.

What is evident in figure 6 is the variation that exists in the physiological load of the brigade members in the drills studied, both at sea level and in geographical height. For this reason, in ergonomics, the case-by-case analysis in extreme work is very important to analyse the differences in the distribution of the physiological load, in order to find ways of assigning tasks for a better distribution of the workload. To illustrate the differences in the load distribution, figure 7 shows, separately for sea level and for geographic altitude, the distribution of the heart rate of the worker who in each case reached the highest overload and a colleague who worked with lower heart rates. In the case of sea level, the worker who reached a peak of 191 beats was responsible for the immobilization of the patient, while the person who reached lower levels, with some isolated peaks, was support staff, without clearly defined role. On the other hand, in the case of the drill at geographical height, the highest heart rate corresponded to a worker who actively participated in all the stabilization manoeuvres and in complex tasks carried out inside the cabin and in the descent of the injured person from the cabin to the ambulance. For its part, the worker with the lowest heart rates performed support tasks in the cabin. 

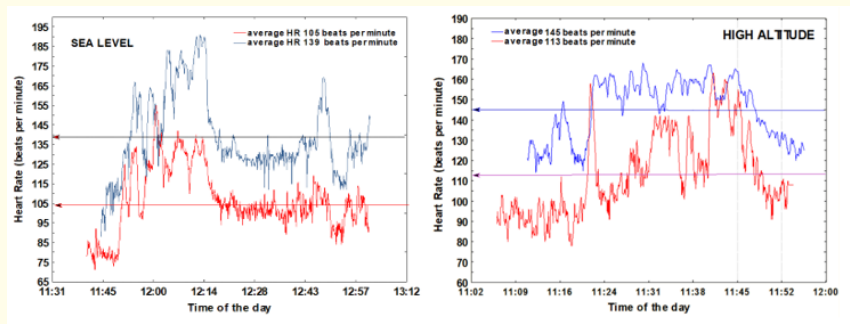

Figure 7: Examples of differences in physiological workload of two workers who were part of the drill at geographical height and of two workers who participated in drills at sea level.

A detail that can be seen in figure 7 is that the rescuers who work with the highest loads, in both cases, in the 15 minutes following the end of the drill, while changing clothes and ordering materials, maintain high heart rates. In other words, due to the intensity of the effort, it takes them longer to recover. The question that arises is: what would happen in a real emergency if such activities are prolonged in time? The information presented is a warning voice and it is important to note that there is evidence that reveals that one of the main risks in serious emergencies is collapse due to overexertion. This is highlighted by the National Fire Protection Association (NFPA) of the United States, who in the mortality statistics of brigade members during 2019 establish that $44 \%$ of deaths during emergencies were due to sudden death associated with overexertion and stress [9]. They also point out that this figure close to $44 \%$ has been maintained in the last 10 years.

Returning to the results of this study, the information collected reveals that BMI has a directly proportional relationship with the increase in heart rate in the drills studied, but it is also true that the imbalances in physiological load could be due to organizational issues. In this sense, one situation does not rule out the other, and both illustrate the complexity of the problem. For this reason, in future studies, in addition to the health exam and BMI registration, better criteria should be used to assess the physical fitness of the brigades. Furthermore, it should be important to develop, together with rescuers and their leaders, strategies of approaching the drills to analyse the work with a systemic perspective. Basically, it is nothing more than assessing the intensity of the efforts and distributing the tasks in a balanced way, to ensure control of the emergency in the shortest possible time and without risks for those who perform the tasks.

In addition to improving the organization to control emergencies, it is also necessary to consider the needs and limitations of the brigade members. With regard to physical fitness, in the NFPA (2020) document, they comment on a program called "healthy heart" for the prevention of heart attacks through exercise and diet that has been applied since 2003. In Chile, there are also very valuable experiences in rural fire brigades. Studies during real fires and drills have made it possible to improve the organization of crews and propose criteria for the medical, physiological and psychological selection of the brigade members [2]. It has also been very important to motivate them to participate in training programs directed by specialists, which help them maintain and improve their aptitude for these difficult tasks [2]. There is no doubt that the results of this study reveal the convenience of developing programs such as those mentioned, if the ultimate goal is to protect the lives of the brigade members, the affected population and preserve the resources of the country and the companies.

\section{Conclusion}

The results of this study allow to conclude that:

- The physiological load in the three drills studied was high, both at sea level and at geographical altitude.

- In the studies it was observed that some workers reached peak cardiovascular load close to $100 \%$ of their maximum level.

- A significant trend was observed, revealing that workers with higher BMI had higher average heart rates than their normal-weight colleagues.

- In the three drills, a significant imbalance in the physiological workload was observed, which requires a more detailed and participatory review of the distribution of tasks and the organization of the integrated emergency care systems.

- It is also recommended that the emergency brigades participate in regular physical training programs and educate them in eating habits to reduce their trend to overweight. 


\section{Bibliography}

1. United Nations Office for Disaster Risk Reduction. "UNISDR Annual Report 2017". UN (2018).

2. Apud E., et al. "Ergonomía en el combate de incendios forestales”. $1^{\text {st }}$ edition. Concepción, Chile: Edition. Valverde (2002).

3. Apud E and y Meyer F. "Factors influencing the workload of forest fire-fighters in Chile". Work 38.3 (2011): 203-209.

4. WHO. "Obesity: Preventing and Managing the Global Epidemic: Report of a WHO Consultation on Obesity" (2000).

5. Apud E., et al. "Guía para la evaluación de trabajos pesados". $1^{\text {st }}$ edition. Concepción, Chile: Edition. Trama (2002).

6. Apud E and Oñate E. "Evaluación de la carga fisiológica de trabajo con fines ergonómicos en actividades mineras que se desarrollan en altura geográfica". Journal of Medical Sciences and Health 6.2 (2020): 131-141.

7. Moraga FA., et al. "Aerobic Capacity, Lactate Concentration, and Work Assessment During Maximum Exercise at Sea Level and High Altitude in Miners Exposed to Chronic Intermittent Hypobaric Hypoxia (3800 m)". Frontiers in Physiology 10.1149. (2019): 01149.

8. Mourot L. "Limitation of Maximal Heart Rate in Hypoxia: Mechanisms and Clinical Importance". Frontiers in Physiology 9.972 (2018): 00972.

9. "Firefighter deaths by cause and nature of injury". National Fire Protection Administration (2020).

\section{Assets from publication with us}

- Prompt Acknowledgement after receiving the article

- Thorough Double blinded peer review

- Rapid Publication

- Issue of Publication Certificate

- High visibility of your Published work

Website: www.actascientific.com/ Submit Article: www.actascientific.com/submission.php Email us: editor@actascientific.com

Contact us: +919182824667 